\title{
Coastal Risk Cultures: Local and Regional Formation of Knowledge and Action
}

\author{
Grit Martinez* \\ Ecologic Institute, Berlin, Germany
}

This paper deals with how culture is expressed through the interplay of socially, politically, and economically driven processes and practices in place-based biophysical contexts as well as the role played by narrative expressions in the formation of coastal risk management, knowledge and action. It draws upon ethnographic, comparative, and historical approaches to understand how culture frames what we know and how we respond differently to risks. The research is based on the theoretical position that interpretation of risks and responses of social groups are shaped by frames of cultural knowledge and values, and investigates the influence resident's values have in shaping the resilience of their community in two coastal regions in Germany and Italy. Information

OPEN ACCESS

Edited by:

Craig E. Colten,

Louisiana State University,

United States

Reviewed by:

Nophea Sasaki,

Asian Institute of Technology, Thailand

Scott A. Hemmerling,

The Water Institute of the Gulf,

United States

*Correspondence:

Grit Martinez

grit.martinez@ecologic.eu

Specialty section:

This article was submitted to Interdisciplinary Climate Studies,

a section of the journal

Frontiers in Environmental Science

Received: 30 June 2020

Accepted: 11 March 2021

Published: 30 April 2021

Citation:

Martinez G (2021) Coastal Risk

Cultures: Local and Regional

Formation of Knowledge and Action.

Front. Environ. Sci. 9:578238.

doi: 10.3389/fenvs.2021.578238 was derived from desk research, semi-structured, narrative interviews, and observation. Specifically, the author was interested in how residents' views and narratives affected their risk behavior, shaped their needs and which role path dependencies and societal contexts played in the formation of risk knowledge, risk management and action. The author found that values, knowledge and identity highly matter in building community resilience. Moreover, the cases illustrate how past and present societal trajectories shape local and regional responses to climate change and why this concerns political decision makers at all levels, who are aiming to mainstream mitigation and adaptation strategies confronting climate change effects and in turn shaping resilience at local and regional levels.

Keywords: culture, values, risk, knowledge, action, resilience (enviromnental), coasts, Europe

\section{INTRODUCTION}

Recent and historic high-impact events have led to significant flood risks in many coastal areas in Europe and across the globe. Specifically, between 1998 and 2018, Europe suffered from over 229 major damaging floods. These floods have caused more than 1600 deaths, the displacement of about half a million people and at least $€ 52$ billion in insured economic losses (EEA, 2019). Moreover, of the thirty largest cities in the world, 20 are in coastal areas and therefore endangered by global climate change and associated sea level rise. Inundation, erosion and other risks are expected to increase due to our changing climate as well as the further development of coastal regions, and will thus require appropriate prevention, mitigation, and preparedness measures (World Economic Forum [WEF], 2019). Consequently, the management and communication of risks has become a major question of public policy (Alexander, 2000). 
Various scientific disciplines are closely linked by their ways of investigation perspectives to the life-worlds of societal groups and individuals. For instance, anthropologists, who consider culture their defining concept, have provided manifold empirical evidence that societal groups are bound by specific shared values that are expressed semantically and materially in place-based contexts (Geertz, 1973; Dove and Carpenter, 2008; Kruper, 2010). Psychologists, sociologists, geographers, environmental historians, political scientists and others have contributed to illustrating the close relationship between risk identification, responses and culture (Brien and Wolf, 2010; Fresque-Baxter and Armitage, 2012; Adger et al., 2013; Clarke et al., 2018; Lemée et al., 2019), leading to the conclusion that society's risk management is to a large extent mediated through culture (Grothmann and Patt, 2005; Kings and Ilbery, 2010; Hards, 2012; Martinez et al., 2018). The focus of this paper is therefore concerned with the cultures of two coastal communities and the contexts in which the values, knowledge and actions of its residents are embedded and modified, and through which they influence the resilience of their communities toward coastal risk management. Chabay et al. (2019) argued that narratives "provide insights into how a desirable future is envisioned and expressed" while "the motivations of individuals and groups for acting in support of, or opposition to, the expressions of vision are strongly influenced and may be inferred from narrative expressions of identity, culture and contexts." The two chosen case study sites (the islet of Ummanz in Germany and the sea-side resort Porto Garibaldi in Italy) are examples further illustrating the deeply layered connectedness which exists between culture and risk management, knowledge and action.

\section{MATERIALS AND METHODS}

This article starts by presenting the two case study sites and methods used in the study. Then, results are discussed concerning the role of local risk cultures in relation to flood risk management and how the formation of knowledge and action relates to resilience and management in the case study sites presented. The discussion also includes recommendation and an outlook on the role of local cultural knowledge for policy making on climate change adaptation.

\section{Description of Case Study Sites \\ Baltic Sea Coast, Germany}

The Baltic Sea is considered the largest brackish sea worldwide, bordering Germany, Denmark, Sweden, Finland, Russia, Estonia, Latvia, Lithuania, and Poland. The water level of the Baltic Sea is subject to constant fluctuations, the highlights of which are storm floods. Low and/or high-pressure systems in the region are frequently able to generate strong winds, which can push water through the sound and belts into the Baltic Sea, raising the sea level in the entire basin. Sometimes hurricane strength can be reached (State Office for Environment and Nature Rostock Coastal Department [SOENRCD], 2009). The heaviest storm surge in the Baltic Sea recorded thus far by level measurements occurred on November 13,1872, causing the sea level to rise to $3.3 \mathrm{~m}$ above average. In Germany, Denmark, and Sweden more than 271 people died, 15,160 lost their homes and 2.860 houses were destroyed (Hupfer, 2019). Even today, exhibits in local history museums and flood marks in communities along the Baltic coastline commemorate this event. Soon after the catastrophe, German newspapers reached out to the population of the newly founded German Empire, making an urgent call for the collection of emergency funds to support the victims' recovery. Moreover, the 1872 flood was both the occasion and starting point for the development of modern coastal protection in Germany. Interestingly, Germany's first chancellor, Bismarck, had his first public office as a dike warden in 1845 where he was "responsible for preventing the Elbe from flooding the countryside" (Feuchtwanger, 2014). Under Bismarck, the Prussian government from then on systemically developed coastal protection measures by planning dikes connected with upstream beach and dune areas. Even today, the design bases for coastal protection structures in Germany are still oriented toward the water levels reached during the 1872 flood, commonly referred to as a "one in a 1000 years flood" (State Office for Environment and Nature Rostock Coastal Department [SOENRCD], 2009). The event is still of scientific interest as the subject of simulation with the help of computer models (Bruss et al., 2009). There are indications that storm surges in the Baltic Sea will become more severe and frequent in the coming century (The BACC II Author Team, 2015).

\section{Ummanz at the Baltic Sea Coast, Germany}

Ummanz is an islet of about 20 square kilometers in size and located in the western part of Rügen, Germany's largest island. It has always been a sparsely populated and dispersed rural area, away from the tourist crowds. In the early 20th century, a 250-m-long bridge was built to connect Ummanz to the main island Rügen. In 1953, electricity reached Ummanz. It is situated in the former GDR, and about 240 residents live on the islet today. High unemployment rates and an aging population characterize the region.

The island lies only a few meters above sea level and is faced not only with the challenges of storm surges, but also has to cope with heightened groundwater levels due to the rise of the sea level and the absence of measures such as levees, dams or designed flood areas. A significant number of residents would be affected by floods (Martinez et al., 2014). It is obvious that Ummanz has always been exposed to natural hazards, and so the risk associated with living on the islet has always been high. Nevertheless, in the past, residents chose to live with these risks in return for agricultural gains on land artificially reclaimed by their ancestors while still feeling sheltered by a ring wall erected in the 19th century-already as a response to the extreme storm surge event of 1872 .

\section{Adriatic Sea Coast, Italy}

Storm surges pose a serious threat to cities of the Adriatic coast, with Venice being hit hardest by floods. Along the Adriatic coastline, 100 kilometers are situated below sea level, exposed to the risk of flooding by sea surges and rivers. "Man-induced or natural subsidence has affected most of these areas, especially 
near the Po Delta area, where an altitude of over $2.5 \mathrm{~m}$ was lost in some places during the past century" (Bondesanf et al., 1995).

\section{Porto Garibaldi at the Adriatic Sea Coast, Italy}

Porto Garibaldi is one of the oldest seaside resorts in northern Italy, an important fishing and tourist destination approximately 100 kilometers south of Venice. Originally a pure fishing village, it today comprises an almost 10 kilometers long stretch of coast, located in the Ferrara and Ravenna provinces, in the region of Emilia-Romagna. Because of its low houses, Porto Garibaldi still gives off the appearance of a fishing village, housing around 4,700 residents today. The port of the town is still home to many fishing boats, but also serves as a recreational port and the mouth of a waterway, which leads from the hinterland to the Adriatic Sea. Every year folklore festivals and events take place, including the celebration of the Madonna of the Sea in June with the traditional procession of decorated boats. Despite such iconic spectacles, the area is exposed to marine floods and erosion. In the past, groundwater and gas extractions have been carried out and wetlands destroyed. Since 1946, 79 major storm events have been recorded (Armaroli et al., 2014).

\section{Frame for Investigating Coastal Risk Cultures in the Case Study Sites}

Generally, resilience is understood as the ability of a system to cope with changes, perturbations or shocks and to return to it's original status, to adjust to the new circumstances and to reduce future risks and vulnerabilities. Perceptions of environmental risks play a critical role when determining the degree to which people are at risk. The significance of culture in understanding why people perceive and act to risk in particular ways is understood as risk culture. Since the beginning of people living together and interacting with the environment, they have constructed stories and with them narratives in verbal, figural or musical forms. Often they deal with events including risks which force actions of the characters involved to overcome those.

Based on the premise that risk assessments are objective analytical processes while risk experiences are subjective "social and cultural processes that shape interpretations of events" (Pidgeon et al., 2003), three interrelated value sets were found particularly relevant for the explanation and interpretation of the risk behavior of people in the examined case studies in Germany (the coastal island of Ummanz in the Baltic Sea) and in Italy (the Adriatic coastal town Porto Garibaldi): Nature and the sea; cultural identity and risk culture; and cultural identity and socio-economic values. These three value sets are important as they explain local interests and attitudes to the coast and sea aesthesia while determining community's identity, perception of risk and consequently the ability to find and implement acceptable solutions to increase adaptive capacity and in turn resilience.

Primarily oral history methods have been applied in this research to explore how socio-cultural, economic and political developments were able to influence the resilience in the two coastal case study areas. Oral history is defined as "a process of collecting, usually by means of tape-recorded interview, reminiscences, accounts, and interpretations of events from the recent past which are of significance." (Hoffmann, 1984 p. 68). In addition, participatory observation was carried out involving active looking, informal interviewing and writing field notes (DeWalt and DeWalt, 2002).

Further materials were viewed in archives and museums as objects and sources that survive in collections demonstrate appreciation of thoughts and activities of people of the past and are often engrained in the collective culture of a community acknowledged as material and immaterial heritage. For this study the author visited the archive of the community of Ummanz and the cultural history museum of the City of Stralsund situated nearly located to the islet of Ummanz (Germany) and the museum of traditions and cultural material "La Tratta" in Ferrara as well as the manufacture of marinades museum in Comacchio (Italy), both in the province of Emilia-Romagna where the case study site Porto Garibaldi is situated. Hence, the types of data used in this paper derived from interviews/participatory observation (such as affective, emotional and other forms of expressions, and knowledge) and archival materials (such as chronicles, letters, photographs, paintings, or others).

\section{Data Collection and Data Analysis}

The investigations mainly used semi-structured qualitative interviews and observation with the intention of seeking different types of information from a historical and a personal level from the residents in the cases. Interviewees were selected through a small pool of initial informants suggested by partners working in the case study sites who in turn nominated other participants through their social networks. The focus of the interviews was to understand perceptions around climate change in general and coastal risks in particular, the local resident's culture of coping with and adapting to these risks, and the prerequisites for implementing adequate risk reduction measures. Interviews were guided by a protocol of written questions grouped into three categories: (1) cultural values; (2) coastal risk perception; (3) risk management and action. The length of an individual interview could vary between 1 and $2 \mathrm{~h}$. Questions encouraged detailed rather than short answers as well as the bringing up of topics which interviewees considered relevant to the conversation. Conversations took place in comfortable environments such as meeting rooms, private homes or at the beach so that interviewees could entirely focus on the conversation.

In total, 24 interviews were conducted. With the agreement of the interviewees, conversations were recorded and later transcribed. The transcription followed the recording and hence contains characteristics of the oral history method such as partial and unfinished sentences or repetitions. The transcriptions were analyzed using the qualitative data software MAXQDA in order to identify common and different themes and development lines amongst the interviewees according to the three interview categories: (1) cultural values; (2) coastal risk perception; (3) risk management and action. Expressive quotes are highlighted in italics with the purpose of exemplifying the sentiments expressed as explicitly as possible. For illustrative purposes, some quotes are exemplarily assigned to the three interrelated value sets (Nature and the sea; cultural identity and risk culture; cultural identity and socio-economic values) which are in detail explored 
in the sections below for each of the case study sites (Ummanz and Porto Garibaldi). In aggregated form the essence of the quotes are presented in Table $\mathbf{1}$ in the "Discussion" section. The archival research occurred after the interview process and was used to contextualize the coded interview data. Handwritten documents such as the chronicle of the community of Ummanz (Figure 1) were acknowledged and materials objects viewed which demonstrate the heritage of fishermen, farmers and residents in the two case study sites. Both data sets are crucial as the enable to analyze the activities explaining how the past shaped their motivation for the present.

\section{Ummanz}

\section{Nature and the Sea}

Known for its relatively "unspoiled" nature, Ummanz has recently become a popular tourist location (See Figure 2). In spring and autumn, huge numbers of cranes gather to rest in the shallow waters of the bays and lakes, providing a spectacle of nature for several weeks. The islet belongs to the area of the "National Park of the Vorpommersche Boddenlandschaft," where tens of thousands of birds gather during migration seasons. Residents and tourists alike admire the calm atmosphere on the island. Residents frequently mentioned that Ummanz was:

TABLE 1 | Comparison of Risks, cultural values, risk culture and adaptation measures in Ummanz and Porto Garibaldi.

\begin{tabular}{lll}
\hline No & INDICATOR & Ummanz \\
\hline 1 & COUNTRY & Germany \\
2 & GEOGRAPHICAL FEATURES, TYPE OF & Few meters above SL, island, coast, shoreline, marsh, \\
& ENVIRONMENT, ENVIRONMENTAL RISKS & polder, rural
\end{tabular}

High-impact meteorological events such as storm surges, inundation, erosion and drainage problem

$3 \quad$ MAIN Economic SECTOR(S)

4 VALUES AND BENEFITS: Cultural identity, cultural assets, recreation, nature appreciation

\section{CULTURAL ASPECT IN SOCIETY: Values} people attribute to their places; the level of risks they associate with the environment in which they live and the beliefs they hold about control and to adapt to its effects, accumulated social memory related to hazards GOVERNANCE: administrative practices in coastal management and functioning public services

ECONOMY: production practices, entrepreneurial capacity, ownership

6 RELATION BETWEEN SOCIETY, GOVERNANCE AND ECONOMY: e.g., (mis)trust, (lack of) cooperation, lack of knowledge

7 HOW DO CULTURAL ASPECTS IMPACT RESILIENCE? Awareness, openness, the ability to cope with changes
Agriculture, ecotourism, conservation, nature protection Cultural identity based on a strong sense of place including a sense of security via a coastal protection dike (historical ring-wall); rich cultural heritage including myths, legends and a local dialect; cultural assets such as famous church altar of cultural and historical importance; nature appreciation such as scenery, aesthetics, wildlife; nature conservation

SOCIETY: Potential risk levels are perceived as not very high, subjective risk awareness seems to be influenced by trade-offs e.g., agricultural gains from reclaimed land of ancestors and the erection of a ring-wall in the past;

GOVERNANCE: Trustworthy welfare system ranging from social security to coastal protection and risk management (dike building in the past); coastal protection is a federal responsibility;

ECONOMY: weak economy (agriculture, ecotourism), modest unemployment rates due to new sources of income through ecotourism

The assistance of the state is not welcomed; feeling of loss of agency (the islanders have less and less power to enhance their resilience) has grown and there is a sense of hopelessness; tension between coastal authorities and residents; islanders believe the state should rebuild the ring-wall and protect built environment as well as reclaimed farmland

Memories and knowledge of land reclamation and appreciation of the successes of it have passed on from one generation to the next, shaping a sense of holding on to the current protective measure although it is in bad shape; competency and ability to cope with disaster and setbacks are greatly overestimated partly due to the lack of personal experiences with extreme events but also due to mistrust toward coastal authorities

\section{Porto Garibaldi}

Italy

Few meters above SL, coast, unique delta ecosystem, forest, wetland, semi-urban and rural settlements

High-impact meteorological events (sea and river side) such as storm surges, flash floods, landslides, erosion and salt intrusion

Tourism, agriculture, fishery, automobile industry Cultural identity based on attachment to food and wine production and a rich farming and fishing tradition, strong entrepreneurial thinking; intangible cultural heritage linked to legends and festivities; recreational services for residents and tourists; partially man-modified coastline and hinterland with extensive touristic buildings and maritime transport

SOCIETY: high risk perception of residents especially owners of establishments near the sea; direct experiences of severe natural hazards in the recent past;

GOVERNANCE: high level of bureaucracy, significant gaps between planners' intentions and planning outcomes e.g., in coastal protection,

ECONOMY: tourism is the strongest sector followed by agriculture, food production and fishing, strong entrepreneurial capacity

Trust and cooperation exist within the community; residents believe more could be done by the authorities to communicate risk and to implement adaptive measures to increase resilience of the area

Location's beauty, rich history and culture are a source of pride; residents have limited access to information on risk mitigation but high individual capacity to cope with risks due to a strong entrepreneurial tradition; high flexibility in acting upon known risks; strong network of beach businesses established for purposes such as construction of winter dunes

Table adapted from Urbanc and Martinez (2020). 


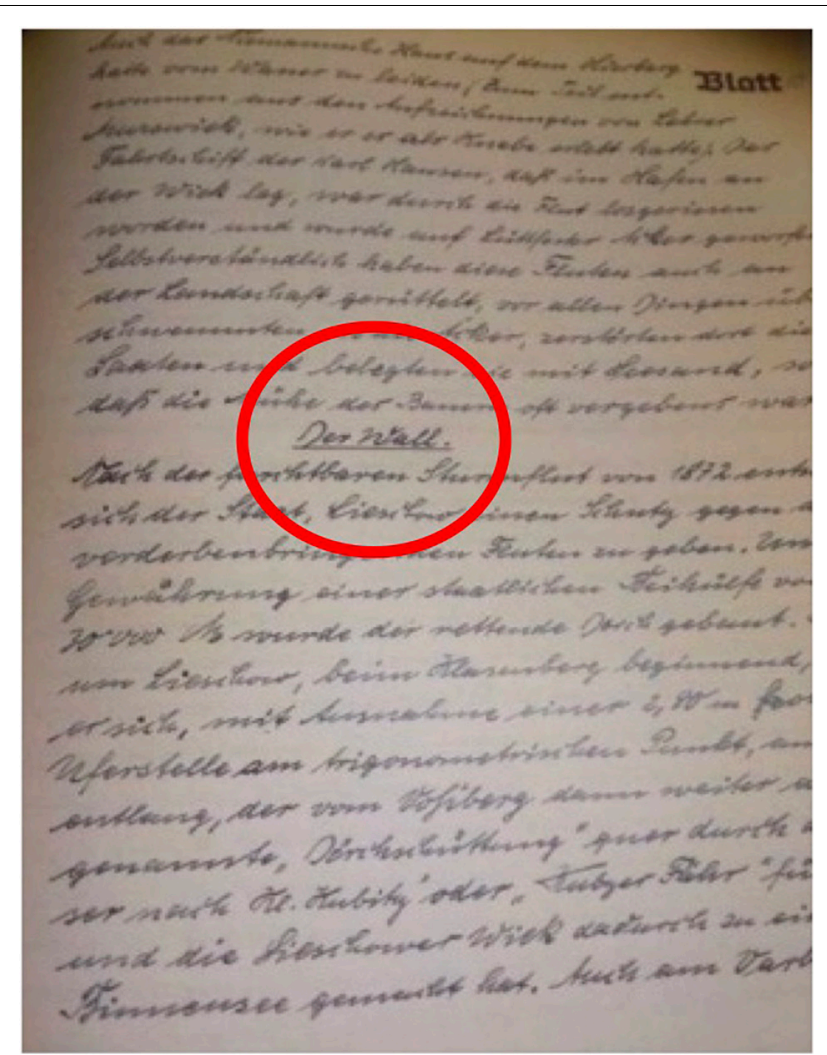

FIGURE 1 | Page from the village chronicle reporting about the construction of the ring dike ("Der Wall"-highlighted in red color). Source: Collection, Rita Hoff, annalist of Ummanz.

(1) "A nice quiet corner which many like to visit... Guests keep saying that we should be careful that nobody destroys this for us... We have unspoiled nature, we have deer and wild boar... we have migratory birds in spring and autumn, we get up to 20,000 seabirds, this is quite a spectacle."

\section{Cultural Identity and Risk Culture}

From the late middle ages on, the sparsely populated island belonged to the nearby Holy Spirit Hospital in Stralsund on the main land. As a result, city dwellers exercised their rule over the island for centuries on behalf of the church foundation. However, they also gave gifts to the islanders: For instance, in the 18th century, Stralsund merchants, who had acquired a precious carved altar from the late Gothic period, originally made 1520 for the English church in Antwerp, donated the altar to the church of Ummanz' village Waase. The extraordinarily strong storm surge of 1872 with water levels above $3 \mathrm{~m}$ had threatened this and other valuable material goods and in the same year, the islanders already decided to erect a ring wall surrounding their settlements and scattered farmlands. Of course, this was only possible with the support of the Prussian state. The village chronicler reports:

(2) "After the devastating storm surge of 1872, the state decided to give protection against the destructive floods. A rescuing dike was built with a state subsidy of 30,000 mark" (Chronicle of Ummanz, author's translation, Figure 3).
It can be assumed that the awareness of their biophysical vulnerability has led the people of Ummanz to hold on to the conviction that the ring wall is a major protective adaptive measure to secure the islet, their property and their lives on it. This has enhanced the islet's resilience to natural hazards, understood as the capacity of the people of Ummanz to knowingly live and cope with this high-risk coastal environment. The following quote of a resident can be seen as a generally valid mind-set representative of the islanders:

(3) "I am often asked are you not afraid for your house? But we have the wall and therefore nobody feels threatened by water here."

In the early 20th century, the ancestors of today's islanders made large parts of the diked land arable. The preservation of this land, its material, but above all, intangible value is important for many islanders today. Likewise, the material threat from flooding has always remained present on the island, since a large part of the claimed agricultural land is being kept dry by the communal operation of pump stations.

\section{Cultural Identity and Socio-Economic Values}

For centuries, fishing and later agriculture were the two main sources of income for the islanders. After the Second World War and the separation of Germany, Ummanz became part of the German Democratic Republic (GDR). Through land reforms, the islet received a different legal status and soon land owned by individual farmers became organized through cooperatives. Due to its peripheral location, the economic situation on the islet has always been challenging. With the exception of the years 1949-1989, in which Ummanz hosted a state-owned farm with more than 7,000 head of cattle and a fishery, agriculture is of lesser importance today and usually exists in combination with other utilization concepts such as ecotourism, while fishery has become almost extinct. About these years residents reflected by stating:

(4) "The state farm had 300 employees at that time, sometimes more, sometimes less in a full-time job but they were employed and I must say that we lived quite well then," while another resident pointed out that: (5) "The families here used to live from fishing. . Nowadays fishermen are becoming fewer and fewer."

Indeed, fishery saw a sharp decline after the German reunification to the extent that only a few families continued to carry on their inherited craft. In combination with the promotion of tourist attractions such as crane watching, hiking, horse riding and other forms of ecotourism, agriculture continues to be a source of income. Today, cultural identity and socio-economic values of the islanders are built very much around farming traditions blended with tourist attractions like crane and bird watching, including breeding horses instead of cattle.

\section{Resilience}

In Germany, the right for protection only extends to builtup inhabited coastal areas. Recently, building permits near the coast are rarely granted. Not surprisingly, conflicts between the residents of Ummanz and the coastal protection authority arose 


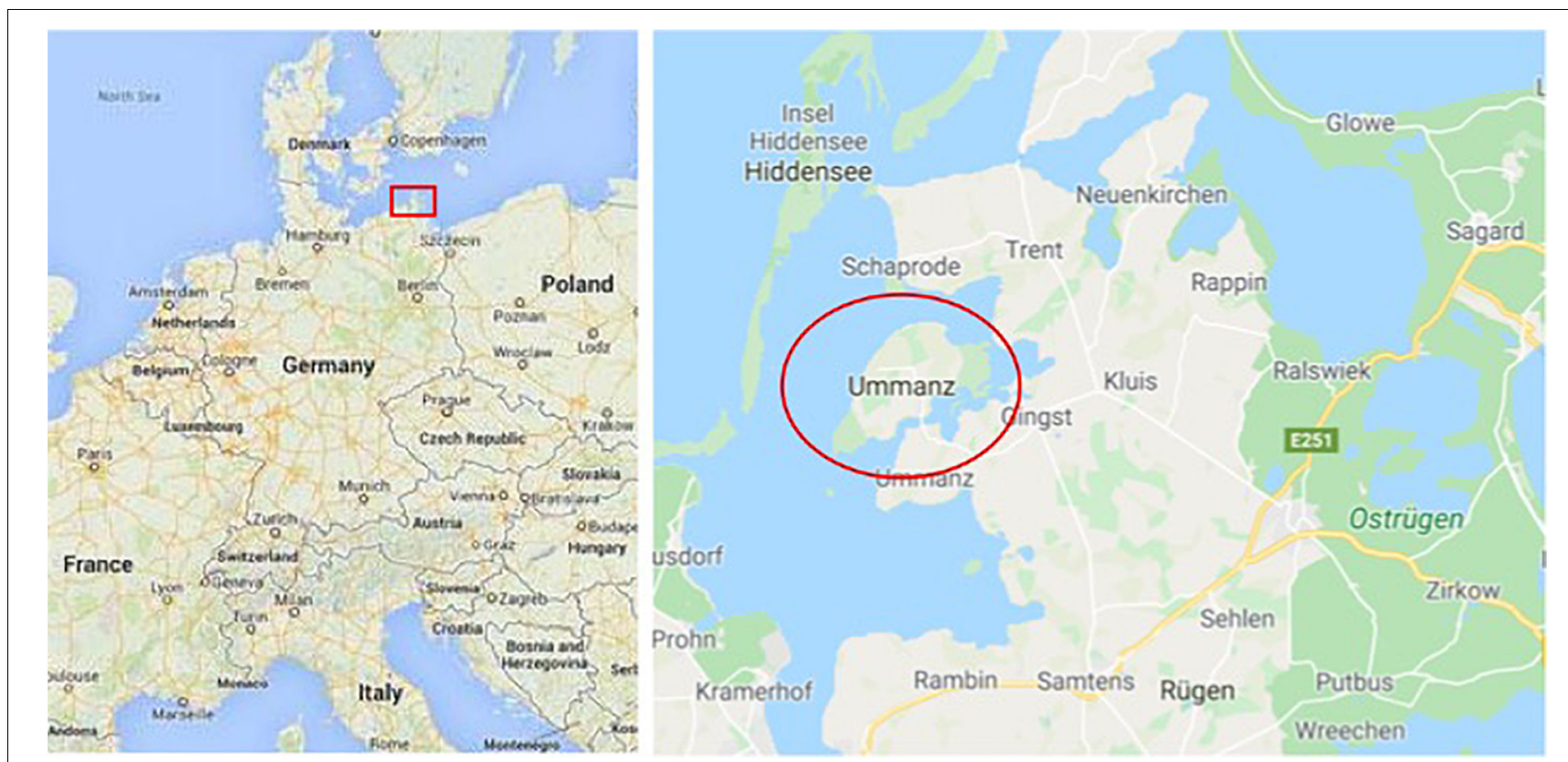

FIGURE 2 | Map of Ummanz. Source: Created by using map data ๑ 2020 Google/INEGI.

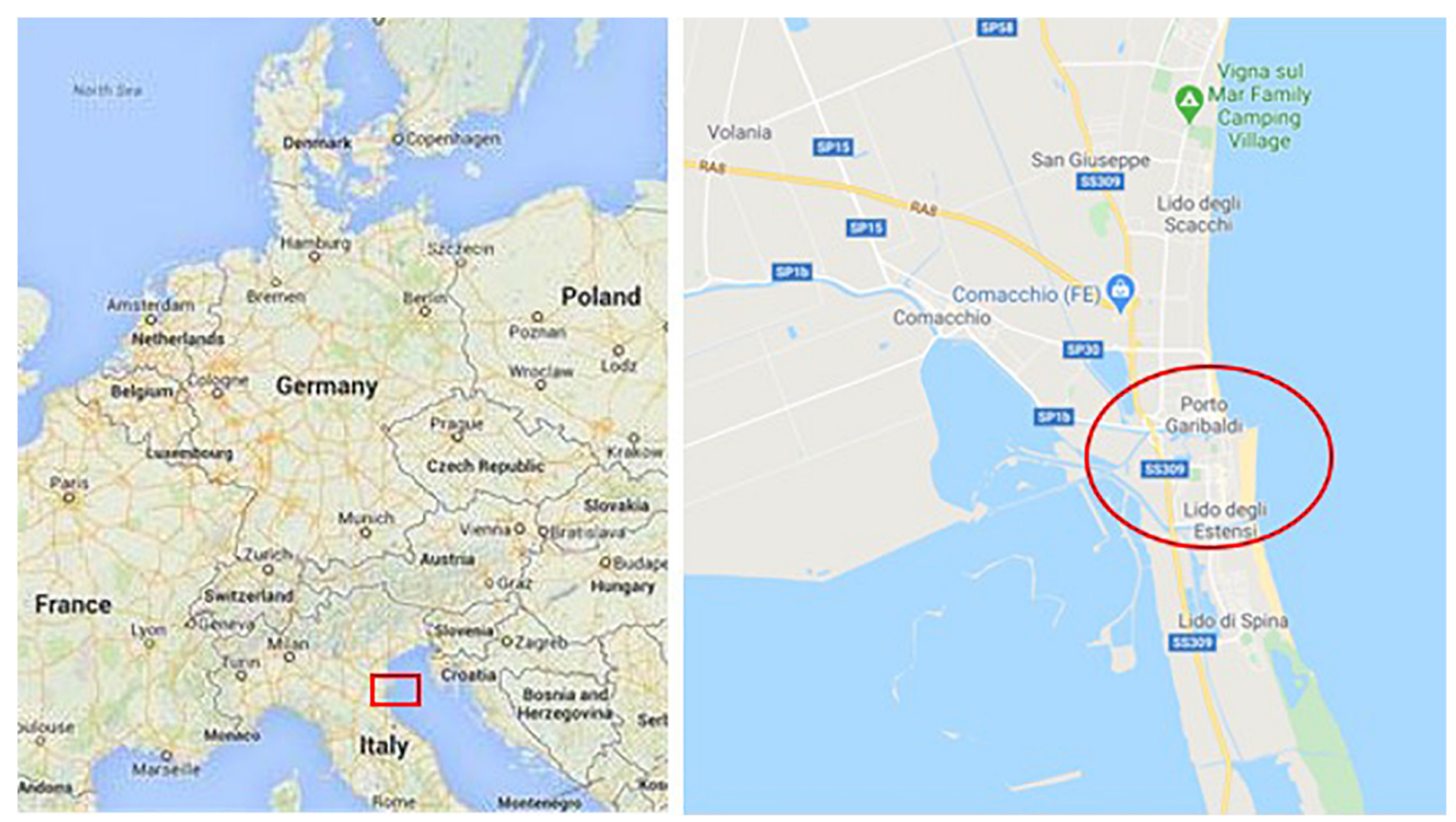

FIGURE 3 | Map of Porto Garibaldi. Source: Created by using map data @ 2020 Google/INEGl.

with regard to safeguarding agricultural land on the islet. The community favors the preservation of the existing structure of the ring wall erected in 1874, which, by now, is in bad shape, while the authorities call for a so-called crossbar solution. This would mean building a new dike across agricultural land, eventually losing some of it to the sea but protecting the inhabited parts of the island from storm surges that may reach the historic heights of the 1872 flood. This coastal protection concept proposed by the state is seen by the islanders as a threat to the hardwon community identity and important intangible values, as many coastal areas have been actively reclaimed by the sea as a resident noted: 


\begin{abstract}
(6) "In 1850 the embankment of the island of Ummanz was started because the farmers suffered from the changing water levels, the big storm tide in 1872 tore everything away but the construction continued and it ended in the 1880's and the ring dike around the island of Ummanz was closed and now within the framework of the renaturation and creation of compensation areas the dikes that had only been used for agricultural purposes should be removed and a new dike should be built partly over the island where there are only dwellings."
\end{abstract}

Skepticism toward state-led planning measures seems to be high in Ummanz, which could be due to experiencing the transition to a new political and economic system after the German reunification, which led, among others, to the decline of formerly prosperous economies such as fishing and cattle breeding (Martinez et al., 2014). To date no further coastal risk measures have been implemented in Ummanz. Locals seem to prefer the status quo of being highly vulnerable to storm surges (since the current ring-wall is in bad shape) to a perceived loss of their cultural identity and economic sources when accepting a crossbar solution. This unsolvable conflict in Ummanz is closely linked to economic factors since the restoration of the ring wall option favored by the community would cost nearly twice as much as the crossbar option. As shown by the review of the history of the construction of the ring walls presented above, the stage for this conflict had already been set in the 19 th century.

\section{Porto Garibaldi \\ Nature and the Sea}

Being the largest natural reserve in the region and a UNESCO World Heritage site, the area and its hinterland are characterized by the presence of wide lagoons, wetlands and canals. Most of the territory is extremely low-lying, with elevations at the coast ranging between 0 and $2 \mathrm{~m}$ above, and the hinterland being below mean sea level. The area has a high historical value: Etruscans and Romans established the first settlements. Because of the presence of many canals, the area is called little Venice.

Residents acknowledge:

(7) "It can be considered one of the most beautiful stretches along our coastline, where you can still find natural characteristics and also some stretches where can observe the natural dynamics of the coastal zone."

(8) "It is a coastal area with a beach and despite some urbanization there are still some relicts of natural areas for great landscaping value."

\section{Cultural Identity and Risk Culture}

Most of the regions of modern Italy have rich cultural traditions, perhaps slowing down the idea of a central unified Italian state in the past. The Emilio-Romagna region is especially known as one of the wealthiest and most developed regions in Italy and Europe alike, featuring seven UNESCO World Heritage Sites (Emilia Romagna, 2020) and a strong economy due to automobile and food production.

The people of Porto Garibaldi take pride in their identity of being fishers in one of the wealthiest regions of Italy. As one resident noted:

\section{(9) "(...) the whole culture of the Comacchio area is based on fish} and eel."

While the cultural identity of the people in Porto Garibaldi is highly shaped by fishery, agriculture and touristic activities also form large parts of the sense of belonging that is anchored in daily practices. Apart from generating material wealth, these circumstances have also shaped immaterial values of the community, promoting for example entrepreneurial thinking and care of cultural tradition. Every year, festivals take place, including the celebration of the Madonna of the Sea in June with the traditional procession of decorated boats, which enter the port.

\section{Cultural Identity and Socio-Economic Values}

Porto Garibaldi holds the potential of joining the rank of iconic touristic villages and towns such as Cervia, Rimini, or Riccione. Famous Romanesque and Renaissance cities such as Ravenna, Ferrara, Modena, and Parma are relatively close by. It is also an area of strategic importance for the Emilio-Romagna region, containing, on the one hand, the largest touristic facilities in Italy while being, on the other hand, a center for many significant industrial activities. Fishing and tourism are key drivers of the socio-economic development of Porto Garibaldi. They represent the centerpiece of the local identity.

High-impact hydrological events, such as storms and flash floods affect the Emilia-Romagna coastline frequently (Armaroli et al., 2014). Coupled with intense urban development along the Adriatic coastline, dune and wetland-systems reduction are a typical sign of the progressing environmental degradation contributing to further vulnerability of the coast (Armaroli et al., 2014). In addition, human activities are intensifying vulnerability to hazards in the area. Urban development at the coastline increased significantly over the past decades, reducing dune and wetland-systems. Not surprisingly, residents noted that:

(10) "It's an area which, especially in the northern part, was subject to quite recent urbanization."

(11) "It's for this reason that this area is now showing a few quite significant anthropogenic effects, especially with regards to beaches, dune fragmentation and so forth."

At the national level, the EU Flood Directive 2007/60/CE and Marine Strategy Framework Directive 2008/56/CE are being used to map vulnerability and risk and to preserve the environment and biodiversity, respectively. In addition, the regional authorities issue planning guidelines at provincial levels through regional territory plans such as dredging of canals to avoid deterioration of the water quality in the lagoons as well as overflow of the canals. However, research on Italian planning processes points out "significant gaps between planners' intentions and planning outcomes, exemplary and ordinary planning practices... political and administrative cultures and practices." (Vettoretto, 2009). Accordingly, residents in Porto Garibaldi report a lack of signals from coastal authorities regarding measures to reduce the risk 
of flooding to people's homes, shops and restaurants. One resident stated:

(12) "Our structure, as well as our culture, is not integrated. We have authorities, internal departments of the region, external authorities."

\section{Resilience}

Residents of the area are highly aware of the risks of flooding and take measures themselves to deal with risks as the following quote illustrates:

(13) "The main hazard affecting the area is related to flooding... The whole area is widely below sea level, especially the inshore and backshore area which is highly vulnerable in the event of sea flooding, considering that these events are quite frequent now."

In the absence of clear signals from authorities, residents became prone to testing risk reduction measures themselves. One interesting example is the ad hoc construction of a measure called winter dune. These are artificial dunes, which are only put together during wintertime to protect near shore restaurants and other establishments from damage and inundation during the usually stormy winter season. The procedure developed in the Porto Garibaldi area and seems to be unknown elsewhere. Over time, winter dunes have demonstrated to be useful in avoiding marine ingression (Harley and Ciavola, 2013). The elevation, width and location of a dune is based on the a resident's experience. Recently, this informal practice was regulated through some compulsory guidelines issued by the local authorities recommending certain parameters regarding heights and slopes of dunes as well as suggestions for the withdrawal of sand. However, residents are still fully self-responsible for the building of a winter dune:

(14) "(.) the local community is very active and even proactive in undertaking actions to protect their own property and coastlines, as can be seen in the case of winter sea storms. They build their own sand dunes, to protect their infrastructure."

\section{RESULTS}

Given the different nature of coastal risk cultures in both case study sites, suggestions for improvement of risk management in the cases are broad in scope but narrow in the way that participation of local residents seem to be underrepresented in public coastal risk planning. For Ummanz establishing communication among the islanders and the coastal authorities would be a primary measure in order to gain trust and broaden mutual understanding on costs and benefits of the certain coastal risk reduction measures at hand. Perhaps a moderated round table discussion on risk reduction measures including the visions of the islanders asking what would they support or even change could be a step forward to overcome the current stalemate situation. In Porto Garibaldi it also seems that the integration between local actors and coastal agencies is somewhat hampered and that more dialog is needed to increase the sharing of good practices to manage the coastline. This could potentially open doors to more collaborative efforts amongst different actors with the goal to develop more long term planning schemes to face disasters in the region in the future.

\section{DISCUSSION}

\section{Role of Cultural Values in Adapting to the Coastal Risks}

The above sections illustrate that the different historical development paths of the two communities, Ummanz and Porto Garibaldi, led to particular material and immaterial value sets, which find their expression in different risk cultures and narratives to cope with risks of storm floods and inundation. Based on interviews and participatory observations the following differences in the risk culture of the two communities have been extracted:

In Ummanz, the memory of past storm surges such as the 1872 flood and its impact are deeply ingrained in the collective mind-set of the islanders (see quote 2). Knowledge is transmitted from generation to generation, for instance surrounding the building of the ring wall, erected in 1873, (see Figure 3). Land reclamation, as well as the appreciation of the success through the creation of polder stations, are also kept alive by the chronicler of the islet. This is contributing to a sense that the residents have been able to cope with storm surges and challenges of inundation, which is an important dimension of cultural resilience. Moreover, for Ummanz, congruence can be noted between the interest of coastal protection connected to the historical ring-wall (see quote 3 ), which the residents hope to see repaired and adjusted to today's protection requirements, and the development of ecotourism. This can be explained by looking back at the municipality's socio-economic development path: The storm surge of 1872 , the subsequent re-development of agriculture and later a breeding farm sheltered by the ringwall, can be understood as a foundation myth, enabling the residents to live protected and comfortable lives in a remote place of natural beauty. Tourism has not been seen as a key driver of the development but rather as an addition to the villagers' identity of being farmers, cattle breeders and fishers (see quotes 1, 4, and 5). Apart from generating some modest wealth on individual household levels, this has also shaped the immaterial value of the community, promoting, for example, a sense of self-sufficiency and self-reliability (see quote 3 ). Ummanz is quite a conservative community in the sense of wishing to maintain these existing values, which are readily found in the land- and seascape as well as in immaterial values such as tranquility and remoteness (see quote 1 ). The coastal protection concept (a crossbar solution across the islet) proposed by the state is seen as a threat to the hard-won identity and immaterial values of the islanders, as many areas have been actively reclaimed from the sea (see quote 5). Ummanz, however, cannot afford the expensive ideal solution of maintaining their historic ring-wall. This results in a stalemate situation preventing risk reduction measures from being implemented at all.

In Porto Garibaldi, the main risk to residents and tourists alike is flooding from the sea and the river, as well as erosion 
and induction of saltwater. Since the whole area lies widely below sea level, the population obviously is very aware of these risks since inundations caused by floods occurred frequently in the past especially during winter times (see quote 13 and 14). As opposed to the community of Ummanz, Porto Garibaldi belongs to one of the wealthiest regions in Italy. Tourism has always been a key driver of developments and represents the centerpiece of Porto Garibaldi's identity. Apart from generating material wealth, this has also shaped the immaterial values of the community, promoting for example entrepreneurial thinking (see quote 14) and investment in culture and infrastructure. Agriculture and especially fishery are of importance (see quote 9). Nature, too, is appreciated-but mostly from a material perspective rather than for the intrinsic or immaterial values associated with it (see quotes 7 and 8). The need for coastal protection is generally accepted. Protection of the community's material values as a basis for future development is a uniting force in the community. With its culinary heritage, famous restaurants, wine tasting establishments and food markets, entrepreneurs who have their establishments located near the beach or river obviously accumulated a proactive mind-set regarding the protection of their establishments over time (see quote 14).

It seems that due to the absence of clear signals from coastal planning authorities regarding measures for reducing the risk of flooding, residents formed their ad hoc mind-set resulting in the testing of winter dunes, hence contributing to the resilience of their community.

Table 1 captures the mind-sets that characterize the two communities and drive the development of their risk cultures, the knowledge they hold on to and the adaptive measures they undertake or stay away from.

The above-discussed findings show the implications cultural values have for the formation of knowledge and risk management in communities. In Ummanz, the residents are captured in a stalemate situation driven by outrage about proposed coastal state measures, which in their opinion would destroy important parts of their cultural heritage, including their communal identity. In contrast, the residents of Porto Garibaldi utilize the rather restrained approach which the coastal authorities are taking toward risk management to create their own, autarkic safety measures. In the Italian case, the desired future does not compromise ingrained heritage and traditions nor does it seem financially and technically unfeasible to implement own protective measures at an individual level. In Ummanz, however, the scale of the protection needed is clearly beyond the financial and human capacity at an individual household level as well as at the level of the general community. The narratives of the ring-wall, which safeguarded the islanders for generations is deeply ingrained in the present risk perception and risk culture of the residents. The specific culture and contexts in which this narrative became embedded influences the dynamics toward change and collaboration with the coastal authorities in Ummanz. In contrast, in Porto Garibaldi, a culture of entrepreneurial thinking, in addition to financial capacities, spurred intervention in form of the residents actively trying to shape a different coastal management reality.

As the cases from Germany and Italy illustrate, the effects which culture and context can have on individual and communal resilience, are not a triviality. Decision makers and planners do need to pay attention to those "cultural" details, the complexity of local conditions and their path dependencies to build trust as well as to strengthen communication between residents and implementing authorities. At the same time, they should support adaptation measures which respectfully acknowledge a community's traditions and heritage while mediating up-to-date forms of coastal protection as well as adaptation measures and enabling mutual learning.

\section{CONCLUSION}

As a major adhesion between different elements, culture is embedded in all aspects of society. A separation only enables analytical distinction between the rational and the symbolic-emotional aspects of environmental concerns. In this sense, culture is not only a positive factor, e.g., strengthening resilience, it can also prevent progress and increase vulnerability instead. The aim of the research was to illustrate how risk perceptions of residents in two case study sites in Germany and Italy, their values, interests and societal contexts, were negotiated and contested and how they, in the end, resulted in different risk management activities. The risk cultures of the people of the island of Ummanz and in the coastal town Porto Garibaldi are framed by their experiences with floods and shaped by interactions with their cultural values, economic resources and political interventions or the absence of such. In other words, communities are not uniformly vulnerable or resilient. In the case of Ummanz, the reasons for the islander's ongoing vulnerability are primarily of a socio-cultural and economic nature while in the case of Porto Garibaldi vulnerability originally seemed to be rather politically determined and eventually became partly transformed into self-organized resilience of entrepreneurs located near the shore. Hence, to a large degree, the causes and consequences of coastal risks are cultural in nature. Although there is a growing concern amongst policy makers and practitioners to support and empower capacities of communities under changing climatic conditions there is still little systematic understanding of why approaches work at local levels or not and what makes some communities resilient and others less so. Due to insufficiently understood cultural phenomena, which influence risk perception, needs and choices of measures, the concept of climate resilience has not yet reached its full potential. Recognizing the importance of local cultures in the process of developing and implementing coastal risk reduction measures and programs is therefore paramount.

Since coastal regions share particular governance and risk management approaches as well as natural resource and built environment practices, using a Climate Resilience Index, as 
recently suggested by Smith et al. (2019), can support policy makers in measuring a community's resilience in relation to socio-ecological impacts of natural hazards. However, due to the possibility of a high divergence of historical and socio-cultural path dependencies, values and contexts, varying perspectives from coastal regions across countries, as documented in this research, might result in different measures to adapt to similar types of disasters I order to boost communities' resiliencies.

\section{Recommendation}

This article shows that adaptation and resilience develop on the basis of socio-cultural-economic traditions and evolutions. It demonstrates that values evolve alongside the socio-economic developments of a community, which in turn is influenced by the political and wider economic environment. In order to promote participative planning processes and through these communication and cooperation between diverging interests, it therefore pays to look at the central values that determine community identity and attitudes. Reference is necessary to local interests, values and attitudes e.g., to the coast and sea aesthesia in the two case studies under investigation determine community identity and consequently the community's ability to find and implement acceptable solutions. In order to be able to successfully plan, implement and communicate adaptation measures and strive for resilience, knowledge of historical, cultural and socio-economic development paths and key community values are essential. These need to be taken into account at every stage of planning, in close co-operation with local actors.

\section{REFERENCES}

Adger, W. N., Barnett, J., Brown, K., Marshall, N., and O’Brien, K. (2013). Cultural dimension of climate change impacts and adaptation. Nat. Climate Change 3, 112-117. doi: $10.1038 /$ nclimate1666

Alexander, D. (2000). Confronting Catastrophe: New Perspectives on Natural Disasters. Oxford: Oxford University Press.

Armaroli, C., Harley, M., and Ciavola, P. (2014). The Case Study site of Porto Garibaldi-Bellocchio. Available online at: https://coastal-management.eu/node/ 209 (accessed April, 2021).

Bondesanf, G. B., Castiglioni, C., Elmis, G., Gabbianellis, R., Marocco, P., Pirazzolift, A., et al. (1995). Coastal areas at risk from storm surges and sea-level rise in northeastern Italy. J. Coast. Res. 11:1354.

Brien, K. L., and Wolf, J. (2010). A values-based approach to vulnerability and adaptation to climate change. WIREs Clim. Change 1, 232-242. doi: 10.1002/ wcc. 30

Bruss, G., Jimenez, N., Eiben, H., and Mayerle, R. (2009). "Bestimmungen von bemessungsparametern ü Küstenschutzanlagen an der deutschen Ostseeküste aufbauend auf szenariosimulationen," in Kuratorium für Forschung im Küsteningenieurwesen (Ed.): The Coast 75 MUSTOK, Archive for Research and Technology on the North Sea and Baltic Coast. doi: 10.1002/wcc.30

Chabay, I., Koch, L., Martinez, G., and Scholz, G. (2019). Influence of narratives of vision and identity on collective behavior change. Sustainability 11:5680. doi: 10.3390/su11205680

Clarke, D., Murphy, C., and Lorenzoni, I. (2018). Place attachment, disruption and transformative adaptation. J. Environ. Psychol. 55, 81-89. doi: 10.1016/j.jenvp. 2017.12.006

DeWalt, K., and DeWalt, B. R. (2002). Participants Observation: a Guide for Fieldworkers. Walnut Creek, CA: AltaMira Press.

\section{DATA AVAILABILITY STATEMENT}

The raw data supporting the conclusions of this article will be made available by the authors, without undue reservation.

\section{ETHICS STATEMENT}

Ethical review and approval was not required for the study which includes human participants, in accordance with the local legislation and institutional requirements. The participants provided their written informed consent to participate in this study.

\section{AUTHOR CONTRIBUTIONS}

The author confirms being the sole contributor of this work and has approved it for publication.

\section{ACKNOWLEDGMENTS}

The KLIMZUG Programme of the German Ministry for Research and Education (case study Ummanz) and the 7th Framework Programme for Research and Technological Development project RISC-KIT grant number 603458 (case study Porto Garibaldi) are acknowledged for the financial support of this study.

Dove, M., and Carpenter, C. (2008). Environmental Anthropology: A Historical Reader. Malde: Blackwell Publishing.

EEA (2019). Available online at: https://ec.europa.eu/environment/water/flood risk/index.htm (accessed April, 2021).

Emilia Romagna (2020). Available onlien at: https://blog.travelemiliaromagna. com/unesco-emilia-romagna (accessed April, 2021).

Feuchtwanger, E. (2014). Bismarck - A Political History. London: Routledge, 26.

Fresque-Baxter, J., and Armitage, D. (2012). Place identity and climate change adaptation: a synthesis and framework for understanding. WIREs Clim. Change 3, 251-266. doi: 10.1002/wcc.164

Geertz, C. (1973). The Interpretation of Cultures: Selected Essays. New York, NY: Basic Books.

Grothmann, T., and Patt, A. (2005). Adaptive capacity and human cognition: the process of individual adaptation to climate change. Glob. Environ. Change 15, 199-213. doi: 10.1016/j.globenvcha.2005.01.002

Hards, S. (2012). Tales of transformation: the potential of a narrative approach to pro-environmental practices. Geoforum 43, 760-771. doi: 10.1016/j.geoforum. 2012.01.004

Harley, D., and Ciavola, P. (2013). Managing local coastal inundation risk using real-time forecast and artificial dune placements. Coastal Engineering 77, 77-90. doi: 10.1016/j.coastaleng.2013.02.006

Hoffmann, A. (1984). "Reliability and validity in oral history," in Oral History: An Interdisciplinary Anthology, eds D. K. Dunaway and W. K. Braun (Nashville: American Association for State and Local History), 68-73.

Hupfer, P. (2019). Die Ostsee - kleines Meer Mit Großen Problemen, E. Schweizerbart'sche Verlagsbuchhandlung. Stuttgart: 111.

Kings, D., and Ilbery, B. (2010). The environmental belief system of organic and conventional farmers: evidence from central-southern England. J. Rural Stud. 26, 437-448. doi: 10.1016/j.jrurstud.2010.05.003 
Kruper, A. (2010). Culture: The Anthropologists'Account. Cambridge, MA: Harvard University Press.

Lemée, C., Fleury-Bahi, G., and Navarro, O. (2019). Impact of place identity, selfefficacy and anxiety state on the relationship between coastal flooding risk perception and the willingness to cope. Front. Psychol. 10:499. doi: 10.3389/ fpsyg.2019.00499

Martinez, G., Armaroli, C., Costas, S., Harley, D. M., and Paolisso, M. (2018). Experiences and results from interdisciplinary collaboration: utilizing qualitative information to formulate disaster risk reduction measures for coastal regions. Coast. Eng. 134, 62-72. doi: 10.1016/j.coastaleng.2017.09. 010

Martinez, G., Frick, F., and Gee, K. (2014). "Socioeconomic and cultural issues in the planning, implementation and transfer of adaptation measures to climate change. The example of two communities on the German Baltic Sea Coast," in Social Dimension of Climate Change Adaptation in Coastal Regions, Vol. 5, eds G. Martinez, P. Fröhle, and H.-J. Meier (München: oekom publishing).

Pidgeon, N., Kasperson, R., and Slovic, P. (2003). The Social Amplification of Risk. Cambridge: Cambridge University Press, 15.

Smith, L. M., Harwell, L. C., Summers, J. K., Bousquin, J., Buck, K. D., Harvey, J. E., et al. (2019). Using re-scaled resilience screening index results and location quotients for socio-ecological characterizations in U.S. coastal regions. Front. Env Sci. 7:96. doi: 10.3389/fenvs.2019.00096

State Office for Environment and Nature Rostock Coastal Department [SOENRCD] (2009). "Ostseedruck Rostock GmbH, 35.Second Assessment of Climate Change for the Baltic Sea Basin (2015)," in Series: Regional Climate Studies, The BACC II Author Team (Ed.), (Basingstoke: Springer Nature).
The BACC II Author Team (2015). Second Assessment of Climate Change for the Baltic Sea Basin. Springer. https://www.springer.com/de/book/9783319160054? gclid=Cj0KCQjw3duCBhCAARIsAJeFyPW7bjUTGi-f5doEjQ_HE_3g1k0TRMUhiXOl8jXapOWPofxC_EeO5YaAsAZEALw_wcB

Urbanc, M., and Martinez, G. (2020). "Culture and Climate Resilience: A Comparative Analysis of Experiences and Practices in Four Case Studies Across Europe," in Culture and Climate Resilience, Palgrave Studies in Climate Resilient Societies, ed. G. Martinez (Cham: Springer Nature), 119-130. doi: 10.1007/9783-030-58403-0_7

Vettoretto, L. (2009). "Planning cultures in italy - reformism, laissez-faire and contemporary trends," in Planning Cultures in Europe: Decoding Cultural Phenomena in Urban and Regional Planning, eds F. Othengrafen and J. Knieling (Farnham: Ashgate), 189.

World Economic Forum [WEF] (2019). Available onile at: https://www.weforum. org/agenda/2019/01/the-world-s-coastal-cities-are-going-under-here-ishow-some-are-fighting-back/ (accessed April, 2021).

Conflict of Interest: The author declares that the research was conducted in the absence of any commercial or financial relationships that could be construed as a potential conflict of interest.

Copyright (c) 2021 Martinez. This is an open-access article distributed under the terms of the Creative Commons Attribution License (CC BY). The use, distribution or reproduction in other forums is permitted, provided the original author(s) and the copyright owner(s) are credited and that the original publication in this journal is cited, in accordance with accepted academic practice. No use, distribution or reproduction is permitted which does not comply with these terms. 